\title{
Cardiac surgery for patients aged 65 years and older: a long term survival analysis
}

\author{
S LIVESEY, * N CAINE, $\dagger$ D J SPIEGELHALTER, $†$ T A H ENGLISH, * J WALLWORK \\ From ${ }^{\star}$ Papworth Hospital, Cambridgeshire; $†$ Department of Community Medicine, University of Cambridge; \\ and $\ddagger$ Medical Research Council Biostatistics Unit, Cambridge
}

SUMMARY Between January 1973 and December 1984, 562 patients aged $\geqslant 65$ had cardiac surgeris at Papworth Hospital. Most had mitral or aortic valve replacements (coronary artery bypas grafting was not introduced for this age group at Papworth until 1977). The overall operativ mortality, defined as death within thirty days or death before leaving hospital, was $7 \cdot 3 \%$. There were no early deaths in patients undergoing coronary artery bypass grafting surgery. Question naires sent to general practitioners in East Anglia traced $86.0 \%$ of the patients who survived to leave hospital. The longer term survival rates for all patients were $88.0 \%$. (95\% confidence intervå (CI) 85 to 91 ) at one year and $74.4 \%(95 \%$ CI 69 to 79$)$ at five years. The rates for those patients who survived the initial few months were $96.3 \%(95 \% \mathrm{CI} 94$ to 98$)$ at one year and $81.5 \%(95 \% \mathrm{CE}$ 77 to 86) at five years and these rates were no different from those in the general population age $\geqslant 65$.

Although cardiac operations are increasingly performed on elderly patients there is little published evidence on the long term survival. Most centres believe that patients should not be denied the benefit of cardiac surgery simply on the grounds of age, though this was not always the case. An editorial in the British Medical Journal in 1968 expressed doubts about the surgical treatment of valvar heart disease in the elderly ${ }^{1}$ and in 1979 Kirklin et al questioned the advisability of coronary artery surgery in patients aged $\geqslant 70^{2}$. But by 1980 the value of cardiac surgery in the treatment of heart disease in the elderly was being increasingly accepted. ${ }^{34}$

The term "elderly" is difficult to define. During the past two decades it has been used to describe different age groups-sixty was considered old by $\mathrm{Oh}$ et al in $1973^{4}$ but later reports have defined 70 as elderly. ${ }^{56}$ None the less, the age of retirement and the pensionable age for men in the United Kingdom is 65 and this was the age group chosen for a specific report by the Coronary Artery Surgery in the United States Study. ${ }^{7}$

Requests for reprints to Mr J Wallwork, FRCS, Papworth Hospital, Papworth Everard, Cambridge CB3 8RE.

Accepted for publication 30 August 1988
For these reasons we chose to review all patient over 65 undergoing cardiac surgery but we also evaluated those over 70 as a separate group.

The proportion of elderly patients undergoing cardiac surgery at Papworth Hospital has increased from 11 in $1973(8.1 \%$ of operations) to $96(16.8 \%)$ in 1984. This had risen further to $120(20.5 \%)$ in 19850 but this group was not included in the survival figures because of the lack of long term data. Figure $\bar{q}$ shows the percentages of operations in patients $\geqslant 6$ 部. each year from 1973 to 1985 .

Several centres have reported on cardiac surgery in elderly patients but most have concentrated ors perioperative mortality and there have been fews reports of long term follow up. We report oug. experience over the twelve years from January 1973 to December 1984.

\section{Patients and methods}

All 562 "elderly" patients who underwent cardiac surgery at Papworth Hospital from January 1973 tథ December 1984 were included in the review. The patients were studied in two age groups-those aged between 65 and 69 years at the time of operation (group 1) and those aged $\geqslant 70$ in group 2 (32 $(57 \cdot 1 \%)$ were male and $241(42 \cdot 9 \%)$ were female $)_{\stackrel{\Phi}{\infty}}^{\circ}$ 


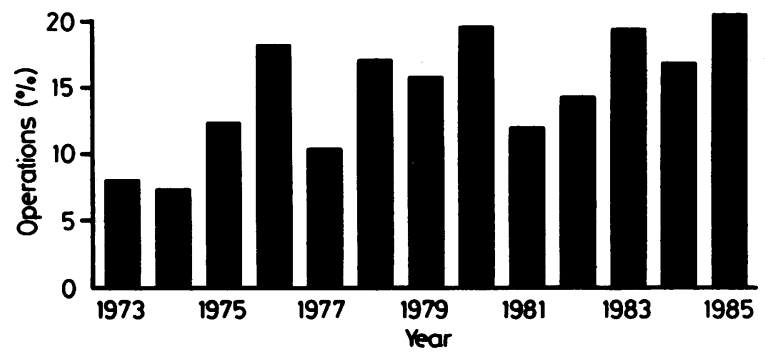

Fig 1 Operations by year 1973-1985.

Table 1 shows the distribution of patients by age, sex, and type of operation.

The term "elective" was applied to those patients who were placed on the routine waiting list to await admission for operation and did not include patients who had operations soon after infarction or those with unstable angina. Patients with impaired left ventricular function were not excluded.

Most patients $(62.1 \%)$ needed operation because of valvar heart disease. Early on in the study many patients with valve disease did not have coronary angiography before operation but in those who did, it was our policy to undertake grafting only if stenoses were severe-that is $>75 \%$ reduction in luminal diameter. We prefer to use bioprosthetic valves in this age group and to treat these patients with anticoagulants for only 8-12 weeks, unless the left atrium is large or there is atrial fibrillation. If a mechanical valve was used we preferred to use a Björk Shiley prosthesis.

We first used coronary artery bypass grafting for patients aged $\geqslant 65$ in 1977 . In both age groups $(\geqslant 65-$ 69 and $\geqslant 70$ ) more men were treated with coronary bypass surgery and for both sexes this operation was performed in more patients in the 65-69 age group than in those aged $\geqslant 70$.

The operations were all performed at moderate hypothermia ( $30-32^{\circ} \mathrm{C}$ ). Myocardial protection was initially by profound local cardiac hypothermia, and cardioplegia was added in 1976. Hospital records provided basic data on the study population and early survival rates. We sent questionnaires to the general practitioners of all those patients who survived to leave hospital to determine longer term survival.

We excluded two groups of patients from the survival analysis: the 73 whom we failed to trace and the 18 patients that we knew had died but for whom we did not have a date of death. Complete follow up data was available for $\mathbf{4 7 1}$ patients from one to 12 years.

\section{STATISTICAL ANALYSIS}

We used life table analysis of annual intervals to assess survival and we compared the two age groups by the Lee-Desu statistic. ${ }^{8}$ For multivariate analysis of survival we used the Cox proportional hazard model. ${ }^{9}$ Proportions were compared by the $\chi^{2}$ statistic and we used multiway analysis of variance to adjust for background factors.

From the mortality statistics for England and Wales published in $1982^{10}$ we calculated the expected survival rates for the study population and we compared these with the actual rates. 1982 was the year closest to the midpoint of the 12 years 19731984 which included a breakdown of mortality per 1000 population by age and sex.

\section{Results}

\section{CHANGES IN CLINICAL PRACTICE}

Table 2 gives a breakdown of data on elderly patients by type of operation before and after 1980 . The number of coronary artery bypass grafting operations carried out after 1980 increased considerably. Even though those given coronary artery bypass grafts tended to be younger $(p<0.001)$, two way analysis of variance showed that, allowing for type of operation, the mean age of patients increased over time ( $p<0.001)$.

Operations in the category "other" included aortic dissections, aneurysms, acquired ventricular septal defects, congenital defects, and complicated valve procedures.

Table 1 Patients by age group and type of operation (number (\%))

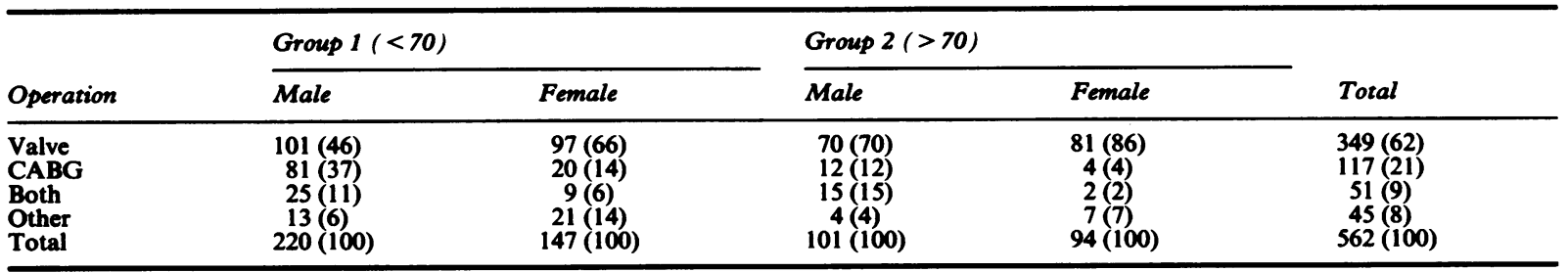

CABG, coronary artery bypass graft. 
Table 2 Patients by operation type and period (number (\%))

\begin{tabular}{|c|c|c|c|c|}
\hline Operation & $\begin{array}{l}\text { Before } \\
1980\end{array}$ & $\begin{array}{l}\text { Mean } \\
\text { Age } \\
\text { (yr) }\end{array}$ & $\begin{array}{l}\text { After } \\
1980\end{array}$ & $\begin{array}{l}\text { Mean } \\
\text { Age } \\
(y r)\end{array}$ \\
\hline $\begin{array}{l}\text { Valve } \\
\text { CABG } \\
\text { Both } \\
\text { Other } \\
\text { Total }\end{array}$ & $\begin{array}{c}154(80) \\
9(5) \\
6(3) \\
24(12) \\
193(100)\end{array}$ & $\begin{array}{l}68 \cdot 3 \\
66 \cdot 0 \\
69 \cdot 7 \\
67 \cdot 1 \\
68 \cdot 1\end{array}$ & $\begin{array}{c}195(53) \\
108(29) \\
45(12) \\
21(6) \\
369(100)\end{array}$ & $\begin{array}{l}70 \cdot 0 \\
67 \cdot 7 \\
68 \cdot 8 \\
68 \cdot 7 \\
69 \cdot 1\end{array}$ \\
\hline
\end{tabular}

CABG, coronary artery bypass grafting.

Table 3 Early mortality by age group and type of operation (\% and proportion)

\begin{tabular}{llll}
\hline Operation & $\begin{array}{l}\text { Group } 1 \\
(<70)\end{array}$ & $\begin{array}{l}\text { Group } 2 \\
(\geqslant 70)\end{array}$ & All ages \\
\hline Valve & $4(7 / 198)$ & $8(12 / 151)$ & $5(19 / 349)$ \\
CABG & $0(0 / 101)$ & $0(0 / 16)$ & $0(0 / 117)$ \\
Both & $18(6 / 34)$ & $6(1 / 17)$ & $14(7 / 51)$ \\
Other & $32(11 / 34)$ & $36(4 / 11)$ & $33(15 / 45)$ \\
Overall & $6.5(24 / 367)$ & $8 \cdot 7(17 / 195)$ & $7 \cdot 3(41 / 562)$ \\
Emergency & $19 \cdot 2(5 / 26)$ & $21.7(5 / 23)$ & $20.4(10 / 49)$ \\
\hline
\end{tabular}

CABG, coronary artery bypass grafting.

\section{EARLY MORTALITY}

Early operative mortality was defined as death within 30 days of operation or death before leaving hospital-40 of the 41 early deaths occurred in hospital. Early mortality for cardiac surgery patients of all ages at Papworth between the years 1973 to 1984 was $4.8 \%$. In the elderly it was $7 \cdot 3 \%(95 \%$ CI $5 \cdot 1$ to 9.5$)-6.5 \%$ in group 1 and $8.7 \%$ in group 2 .

Table 3 shows the operative mortality by type of operation and age group for all 562 elderly patients and for 49 patients who had emergency operations. Analysis of variance shows that once operation type is taken into account, being aged less than 70 and having an operation after 1980 are both associated with a small $(3.0 \%)$ but not statistically significant benefit. The sex of the patient had no influence. Of the ten early deaths after emergency operation, six were in patients who had operations in the "other" category, and the remainder occurred in patients with valve disease.

Figure 2 shows that the overall operative mortality for elderly patients fell from $36.4 \%$ in 1973 to $5.2 \%$ in 1984. The operative mortality after elective surgery alone had fallen from $33.0 \%$ in 1973 to $1.2 \%$ in 1984. In the more recent cohort of patients whose operations took place between 1980 and 1984, there were 232 in group 1 and 137 in group 2. The mean (SD) overall operative mortality in this period was $5.7 \%(21)$ for all patients and $4.0 \%$ for patients who had elective operation. The early mortality for valve

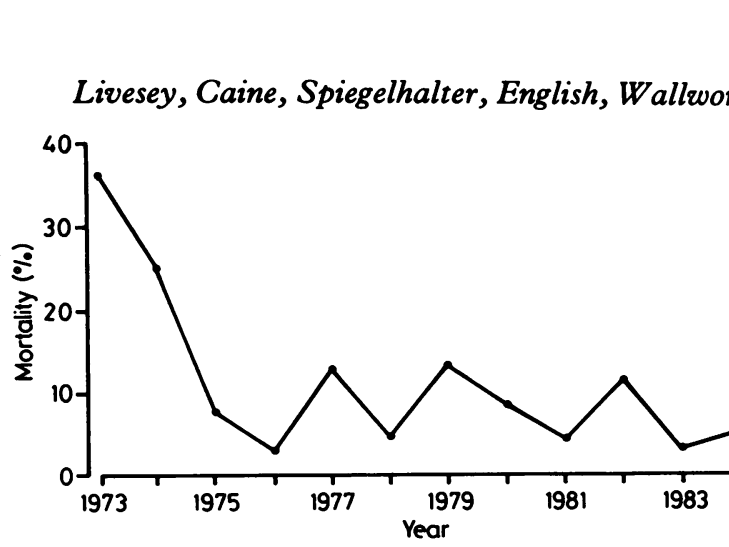

Fig 2 Early mortality 1973-1984.

replacement alone in this five year period was $5 \cdot 1 \%-2 \cdot 1 \%$ for the younger age group and $8 \cdot 1 \%$ fo the over 70 s $(p=0.12)$.

\section{SURVIVAL}

Figures 3-6 show the survival statistics for the elderly patients who died in hospital or were latê traced by questionnaire.

The survival rates for all 471 elderly patients in whom follow up information was complete wete $88.0 \%(95 \%$ CI 85 to 91$)$ at one year and $74.4 \%$ (95\% CI 69 to 79 ) at five years (fig 3). The older age group fared only slightly worse than the younge group $(p=0 \cdot 1)$. The ten year survival rate was $46.5 \%(95 \%$ CI 33 to 61$)$ for all elderly patients $-\frac{0}{2}$ $50.1 \%$ in group 1 and $39.7 \%$ in group 2 . The sex the patient was not an important factor in predicting survival whereas the type of operation was (p < 0.001). (fig 4)

Table 2 shows that only the group with valvar disease provides sufficient data for a comparison of long term survival in patients operated on in differe periods. Figure 5 shows the survival rates for the cohorts of patients undergoing valve surgery before and after 1980. The survival of patients operated on. after 1980 was slightly better but the difference was ne statistically significant $(p=0.67)$.

A multifactorial analysis (Cox proportional hazare model) with stratification by operation showed the the relative annual risk of death associated with bein over 70 at operation was 1.45 , (95\% CI 0.97 to $2 \cdot 16 \%$ that for operation after 1980 was $0.79(95 \%$ CI 0.52 to 1.21$)$, and that for being female was $0.95(95 \%$ 0.65 to 1.39 ). These figures support the findings the single factor analysis-that age may have a slight adverse effect, with a possibility of some improvement in survival over time, and that the ses of the patient has little or no influence.

Coronary artery bypass grafting was firgt performed on patients aged $\geqslant 65$ in 1977 and sinct then there have been no operative deaths from this procedure. Longer term survival data are availabR 


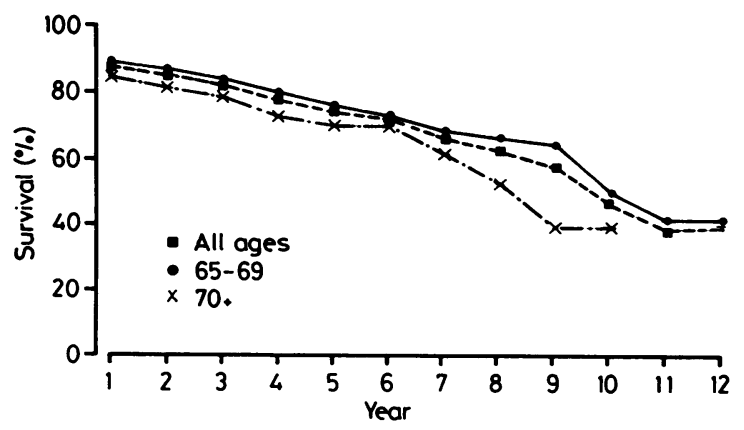

Fig 3 Survival by age of patient.

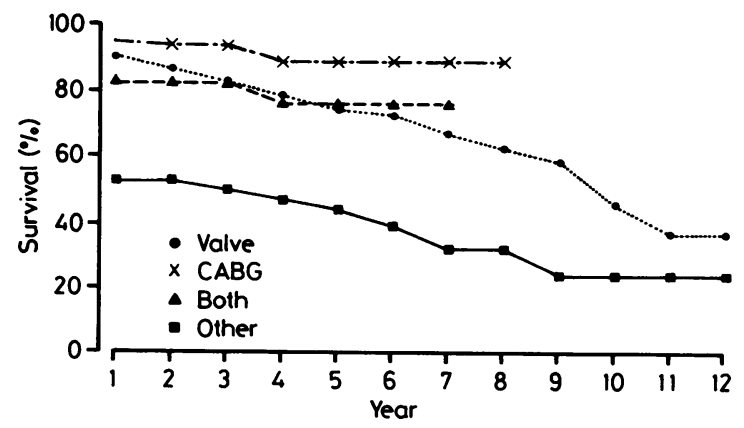

Fig 4 Survival by type of operation.

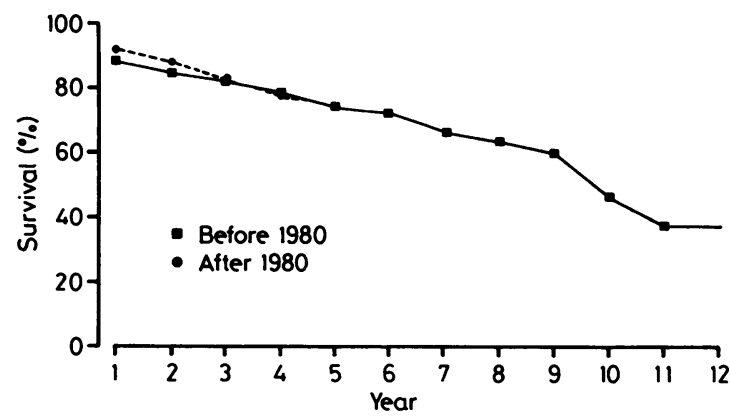

Fig 5 Survival by period of operation.

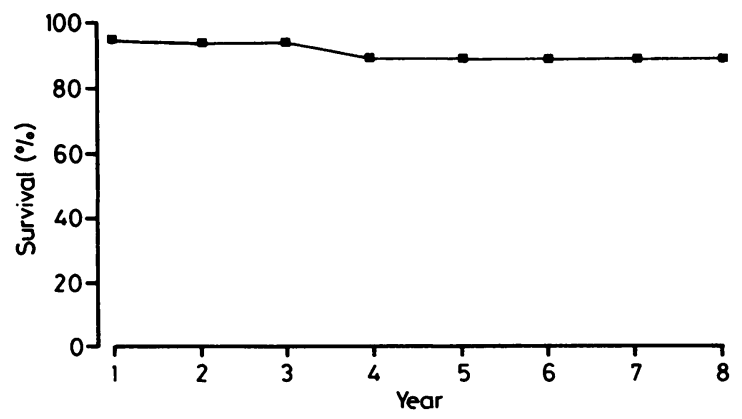

Fig 6 Survival of patients with coronary artery bypass grafts. for 100 out of the 117 patients who had coronary artery bypass grafting (fig 6). The 17 patients who were not traced by questionnaire were excluded from the survival figures. The survival rates were $95.0 \%$ (95\% CI 91 to 99$)$ at one year falling to $89.0 \%$ (95\% CI 81 to 97) at eight years. Of those elderly patients who had an operation between 1977 and 1980 only three have been lost to follow up, and all of those traced are alive.

To assess whether the 73 patients we could not trace were less likely to have survived, we compared their population structure with that of the 489 patients whom we did trace. Similarly, to determine whether the 18 patients whose date of death was unknown were less likely to have survived as long we compared them with the 81 whose date of death was known. The 73 patients whom we failed to trace were no different in age, sex, or type of operation than the patients who were traced-but a higher proportion of these patients had been operated on before 1980 . In terms of age, sex, operation type, or period of operation (before or after 1980) the population structure of the 18 patients whose date of death was unknown was no different from that of the 81 whose date of death was known.

When we compared the expected and actual survival rates in the study population, we found that the expected one year rate was $96.4 \%$ and the actual rate was $88.0 \%$. For the five year rates the corresponding figures were $80.1 \%$ expected compared with $74.4 \%$ actual. But after the 41 early deaths were excluded from the study population we found that the actual one and five year rates for the remaining patients were $96.3 \%$ (95\% CI 94 to 98 ) and $81.5 \%$ (95\% CI 77 to 86 ) respectively. So the survival rate of patients who survived the first months after operation was similar to that of people aged $\geqslant 65$ in the general population.

\section{Discussion}

Although increasing age is usually associated with a higher operative mortality after cardiac surgery ${ }^{11}$ we found an operative mortality and long term survival that would be acceptable for any major surgical procedure. The consistently low early mortality rate for elective surgery and the increasing numbers of patients being operated on each year mark cardiac surgery as being one of the most successful and beneficial forms of operation in the elderly.

The operative mortality for all procedures during the 12 year period $(7 \cdot 3 \%)$ resembles that reported by the Coronary Artery Surgery Study $(5 \cdot 2 \%)$, Bessone et al, $(3.7 \%)^{6} \mathrm{McCa}$ lister et al $(6 \%)^{12}$ and Gann et al $(8 \%)^{13}$ for a much shorter time span. The presence of untreated coronary artery disease in 
484

patients with valve disease, before the subsequent introduction of coronary artery bypass grafting, and improved myocardial protection and the increasing willingness of cardiologists to recommend an increasingly safe procedure to patients earlier in the course of their illness may have all contributed to a general improvement in early mortality.

In the years 1973-1975 early mortality after elective surgery improved considerably and when the changing mix of operations was allowed for we found that in percentage terms the improvement since 1975 was small. However, this should be viewed against the much larger numbers of elderly patients now passing through the unit, the increase in the average age of patients over time, and the broader selection criteria applied to elderly patients. An early mortality rate of $4.3 \%$ was reported from Papworth Hospital in 1978 for valve replacement in 68 patients over the age of 65 from 1973 to $1976 .{ }^{14}$ The overall mortality of $5.0 \%$ for 1980 to 1984 , of 186 patients having valve replacement shows that the expansion of activity in the unit has been managed safely.

An emergency operation will always carry a greater risk than an elective procedure and this is true for the elderly. The early mortality associated with the very small numbers of emergency cases at Papworth has varied widely over the years. Thus although a $1.2 \%$ mortality for elective surgery was achieved in 1984, the overall rate was $5.1 \%$ because early mortality for emergency operation was $30 \%$ in the same year $(3 / 10$ cases), and while there were no deaths after the three emergency cases in 1982, the mortality after elective operation that year was $12 \cdot 0 \%$.

Thus the early mortality in elderly patients continues to reflect the pattern of cases presenting and the tendency in recent years to operate on patients who used to be considered to be too ill for operation.

Mortality from coronary artery bypass grafting is universally less than that associated with valve replacement and although the zero operative mortality we report has rarely been matched, ${ }^{11}$ most centres have quoted a variable early mortality for this procedure (Knapp et al ${ }^{15} 1.1 \%$, Coronary Artery Surgery Study ${ }^{7} 5 \cdot 2 \%$, McCallister et al ${ }^{12} 6.0 \%$ ). This level of operative mortality combined with excellent long term prospects for these patientsalmost $90 \%$ of all patients traced were alive at eight years-should guarantee the place of coronary artery bypass grafting in the treatment of ischaemic heart disease in the elderly, with the same selection criteria being applied as for patients under 65 years old.

The move away from the purely symptomatic treatment of heart disease in the elderly will continue and although any improvement in quality of life these patients may attain awaits formal documentation, an
Livesey, Caine, Spiegelhalter, English, Wallwor蛋

afternoon in the outpatient clinic reassures us that the gains are considerable.

We thank the general practitioners of East Anglia an their staff for their invaluable assistance $i \frac{\bar{f}}{7}$ completing questionnaires and tracing patients an $\vec{g}$ Mrs Rosemary Martin for her help with date processing.

\section{References}

1 Anonymous. Systolic murmurs in the elderly. $\mathrm{Br} \mathrm{Med}$ 1968;4:530-1.

2 Kirklin JW, Kouchoukos NT, Blackstone EH, et d\$? Research related to surgical treatment of coronares artery disease. Circulation 1979;60:1613-8.

3 Jamieson WRE, Thompson DM, Munro AI. Cardia valve replacement in elderly patients. Can Med Assot $J$ 1980;123:628-32.

4 Oh W, Hickman R, Emanuel R, et al. Heart valke surgery in 114 patients over the age of $60 . \mathrm{Br}$ Heart 9 1973;35:174-80.

5 Stephenson LW, MacVaugh H, III, Edmunds LF. Surgery using cardiopulmonary bypass in the elderly Circulation 1978;58:250-4.

6 Bessone LN, Pupello DF, Blank RH, et al. Valỳe replacement in patients over 70 years. Ann Thores Surg 1977;24:417-20.

7 Gersh BJ, Kronmal RA, Schaff HV, et al. Long-term $\frac{t}{6}$ year) results of coronary bypass surgery in patients years old or older; a report from the Coronary Arte Surgery Study. Circulation 1983;68(suppl 11-190-1.

8 Lee E, Desu M. A computer program for comparing samples with right-censored data. Computer Prograng in Biomedicine 1972;2:315-21.

9 Cox DR. Regression models and life tables (wi discussion). J R Stat Soc 1972;B,34:187-220.

10 Office of Population Censuses and Surveys. Mortalit statistics: review of the registrar general on deaths England and Wales. 1984. Series DH1 No.13: London: HMSO.

11 Gersh BJ, Kronmal RA, Frye RL, et al. Coronary arteriography and coronary artery bypass surgerf: morbidity and mortality in patients aged 65 years or older. A report from the Coronary Artery Surgef. Study. Circulation 1983;67:483-90.

12 McCallister BD, Schmeidt M, Reed WA, et Coronary artery bypass in patients over the age of $70 x$ initial and late results [Abstract]. Circulation 1975;52(suppl II) 11-91.

13 Gann D, Colin C, Hildner FJ, et al. Coronary artery bypass surgery in patients seventy years of age afd older. J Thorac Cardiovasc Surg 1977;73:237-41. Ф

14 de Bono AHB, English TAH, Milstein BB. Heart val:e replacement in the elderly. Br Med J 1978;ii:917-9.0

15 Knapp WS, Douglas JS, Craver JM. Efficacy of coronary artery bypass grafting in elderly patien?s with coronary artery disease. Am J Card 1981;47:923-30. 


\section{Notices}

\section{British Cardiac Society}

The Annual General Meeting will take place in Torquay on 22 to 25 May 1990.

\section{Cardiac ultrasound}

The 4th Bristol Cardiac Ultrasound Course will be held at Bristol General Hospital. There are two modules which can be attended individually if desired: on 12 and 13 July 1989 on Cardiac imaging ( $M$ mode and cross sectional) and on 14 and 15 July 1989 on Doppler echocardiography (including colour flow). Further details from Dr Peter Wilde, Consultant Radiologist, Department of Radiodiagnosis, Bristol Royal Infirmary, Bristol BS2 8HW. Telephone (0272) 230000 Ext 2130.

\section{Pakistan Cardiac Society}

The 9th biennial International Congress of Cardiology organised by the Pakistan Cardiac Society will take place in Lahore on 7 to 10 December 1989. For information write to the organising secretary of the Congress at the Department of Cardiology, Mayo Hospital, Lahore, Pakistan.

\section{Correction}

Cardiac surgery for patients aged 65 years and older: a long term survival analysis $S$ Livesey, $N$ Caine, $D J$ Spiegelhalter, $T A H$ English, $J$ Wallwork-The authors apologise for omitting in their paper published in the December 1988 issue (volume 60: pages 480-4) thanks to Mr B B Milstein for his help and acknowledgement to the cardiologists at Papworth Hospital who selected and referred the patients for operation. 